\title{
Effects of the combination of dexamethasone and fibroblast growth factor-2 on differentiation of osteoprecursor cells
}

\author{
JUN-BEOM PARK \\ Department of Periodontics, Seoul St. Mary's Hospital, College of Medicine, \\ The Catholic University of Korea, Seoul 137-701, Republic of Korea
}

Received May 9, 2013; Accepted November 15, 2013

DOI: $10.3892 / \mathrm{mmr} .2013 .1811$

\begin{abstract}
Dexamethasone is a potent modulator of osteogenic differentiation and previous studies have shown that dexamethasone increases the bone formation capacity of osteoprogenitor cells in vitro. Fibroblast growth factor-2 (FGF-2) is reported to have numerous biological activities, including stimulation of cell growth, migration, angiogenesis, wound healing, tissue repair, differentiation and morphogenesis. In the present study, the dose-dependent effect of dexamethasone and FGF-2 on the differentiation of osteoprecursor cells was evaluated. The alkaline phosphatase (ALP) activity test was performed to assess differentiation and protein expression associated with bone formation was measured by western blot analysis. The results showed that the protein content of the cultures grown with the osteogenic differentiation media in the presence of $2 \mathrm{ng} / \mathrm{ml}$ FGF-2 was increased compared with that of the untreated control. ALP activity was increased when cells were treated with dexamethasone, with the highest value at $100 \mathrm{nM}$. The addition of $20 \mathrm{ng} / \mathrm{ml} \mathrm{FGF-2} \mathrm{to} 100 \mathrm{nM}$ dexamethasone showed an increase in ALP activity, however, this was not statistically significant. The combination of $100 \mathrm{nM}$ dexamethasone and $20 \mathrm{ng} / \mathrm{ml} \mathrm{FGF-2} \mathrm{produced} \mathrm{the} \mathrm{highest} \mathrm{expression} \mathrm{of} \mathrm{bone}$ morphogenetic protein receptor-IA and bone morphogenetic protein receptor-II, leading to the highest value of $\mathrm{pSmad} 1 / 5 / 8$ expression. Within the limits of this study, dexamethasone significantly enhanced osteoblast differentiation, however, the combined delivery of dexamethasone and FGF-2 did not produce synergistic effects on osteoblast differentiation under the current experimental conditions.
\end{abstract}

Correspondence to: Dr Jun-Beom Park, Department of Periodontics, Seoul St. Mary's Hospital, College of Medicine, The Catholic University of Korea, 222, Banpo-daero, Seocho-gu, Seoul 137-701, Republic of Korea

E-mail: jbassoonis@yahoo.co.kr

Key words: dexamethasone, differentiation, fibroblast growth factor 2, osteoblast

\section{Introduction}

Dexamethasone is a potent synthetic member of the glucocorticoid class of steroid hormones (1). Dexamethasone is reported to have major effects on a number of organ systems, including the cardiovascular, endocrine, gastrointestinal, ophthalmic and musculoskeletal systems (2). Dexamethasone is a potent modulator of osteogenic differentiation and previous studies have shown that dexamethasone increased the bone formation capacity of osteoprogenitor cells in vitro $(3,4)$. Furthermore, it was reported that dexamethasone acts synergistically with growth factors (5). Fibroblast growth factor-2 (FGF-2) is reported to have numerous biological activities, including stimulation of cell growth, migration, angiogenesis, wound healing, tissue repair, differentiation and morphogenesis (5). In addition, FGF-2 is known to play a critical role in bone growth and development (6-8).

A previous report showed that dexamethasone and FGF-2 are required to maintain cell propagation, alkaline phosphatase (ALP) expression and osteocalcin secretion and act synergistically. However, protein content is FGF-2-dependent and mineralization is dexamethasone-dependent (9). Controversial opinions exist with regard to the combined effects of dexamethasone and FGF-2 in proliferation, differentiation and mineralization. FGF-2, in combination with dexamethasone, were previously found to stimulate the proliferation and osteoblastic differentiation of human adipose tissue-derived mesenchymal stromal cells (10). In another study, dexamethasone increased mineralization, while FGF-2 blocked this activity and the addition of dexamethasone to FGF-2 did not alter FGF-2-associated inhibition (5).

The current study aimed to examine the dose-dependent impact of dexamethasone and FGF-2 on the differentiation of osteoprecursor cells. The ALP test was performed to assess differentiation and protein expression associated with bone formation, including bone morphogenetic protein receptor-IA (BMPRIA) and bone morphogenetic protein receptor-II (BMPRII) and phosphor-Smad1/5/8 (pSmad1/5/8) was evaluated by western blot analysis.

\section{Materials and methods}

Cell culture. Murine calvarial osteoprecursor cells (MC3T3-E1) were plated and cultures were maintained in $\alpha$-minimum 
essential medium ( $\alpha$ MEM) supplemented with $10 \%$ fetal bovine serum, antibiotics [penicillin $100 \mathrm{U} / \mathrm{ml}$ and streptomycin $100 \mu \mathrm{g} / \mathrm{ml}$ (all Invitrogen Life Technologies, Carlsbad, CA, USA)], $50 \mu \mathrm{g} / \mathrm{ml}$ ascorbic acid and $10 \mathrm{mM} \beta$-glycerophosphate (both Sigma-Aldrich, St. Louis, MO, USA). Cells were stimulated with dexamethasone and FGF-2 at a final concentration of $10 \mathrm{nM}$ (D1) to $100 \mathrm{nM}$ (D2) for dexamethasone and $2 \mathrm{ng} / \mathrm{ml}$ (F1) to $20 \mathrm{ng} / \mathrm{ml}$ (F2) for FGF-2. The cultures were maintained in a humidified atmosphere with $5 \% \mathrm{CO}_{2}$ and $95 \%$ air at $37^{\circ} \mathrm{C}$.

Protein measurement. Cells were incubated in $\alpha$ MEM in the presence of ascorbic acid and $\beta$-glycerophosphate for two days. Protein content was determined based on the Bradford method, using the Coomassie protein assay reagent in comparison with a series of bovine serum albumin as internal standards (11). The absorbance was recorded at $595 \mathrm{~nm}$ using the microplate spectrophotometer system (BioTek, Winooski, VT, USA) and results are presented as the percentage of control values.

ALP activity assays. The ALP assay for osteoblast differentiation was performed after incubation. MC3T3-E1 murine calvarial preosteoblasts were lysed with a buffer containing $10 \mathrm{mM}$ Tris- $\mathrm{HCl}(\mathrm{pH} 7.4)$ and $0.2 \%$ Triton X-100 and were then sonicated for $20 \mathrm{sec}$ at $4^{\circ} \mathrm{C}$. Samples were incubated with $10 \mathrm{mM}$ p-nitrophenylphosphate as a substrate in $100 \mathrm{mM}$ glycine buffer $(\mathrm{pH} 10.5)$ containing $1 \mathrm{mM} \mathrm{MgCl}{ }_{2}$ at $37^{\circ} \mathrm{C}$ in a water bath. The absorbance at $405 \mathrm{~nm}$ was measured using a microplate reader (BioTek) and ALP activities were normalized with respect to total protein content $(12,13)$.

Western blot analysis. Osteoprecusor cells were washed twice with ice-cold phosphate-buffered saline and solubilized with a lysis buffer. The lysates were centrifuged at $16,000 \mathrm{x} \mathrm{g}$ for $20 \mathrm{~min}$ at $4^{\circ} \mathrm{C}$ to remove the nuclear pellet. The supernatants were boiled in a sodium dodecyl sulfate sample buffer containing $\beta$-mercaptoethanol. Equal amounts extracts were separated by sodium dodecyl sulfate-polyacrylamide gel electrophoresis and transferred onto polyvinylidene fluoride microporous membranes (Immobilon-P membranes; Millipore Corporation, Billerica, MA, USA). The membranes were blocked for $>1 \mathrm{~h}$ in $0.1 \%(\mathrm{v} / \mathrm{v})$ phosphate-buffered saline and Tween-20 containing 5\% (w/v) powdered milk. Each membrane was probed with the desired antibodies diluted in the same buffer at the recommended concentrations. Each membrane was incubated with horseradish peroxidase-conjugated secondary antibody and then the washed blot was developed using enhanced chemiluminescence detection kits $(14,15)$. Mouse antibodies against BMPRIA, BMPRII and $\mathrm{pSmad} 1 / 5 / 8$ and horseradish peroxidase secondary antibodies were purchased from Santa Cruz Biotechnology, Inc. (Santa Cruz, CA, USA) and Cell Signaling Technology, Inc. (Danvers, MA, USA).

Statistical analysis. Results are expressed as means \pm standard deviations of the experiments. Two-way analysis of variance (ANOVA) with post-hoc tests were performed to determine the combination effects of dexamethasone and FGF-2 using a commercially available program (SPSS 12 for Windows; SPSS Inc., Chicago, IL, USA). A one-way ANOVA was used to compare data within the same groups.

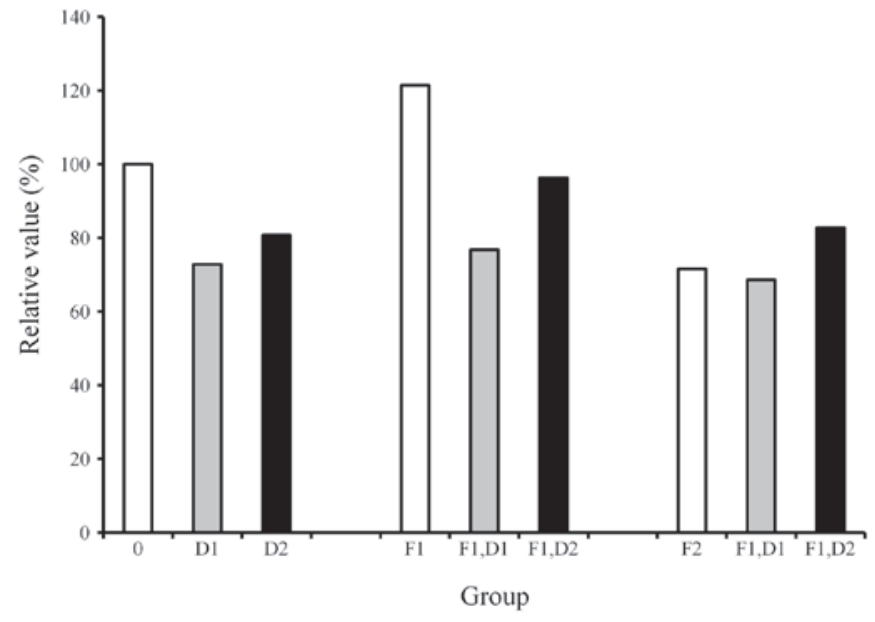

Figure 1. Determination of protein measurement in each group.

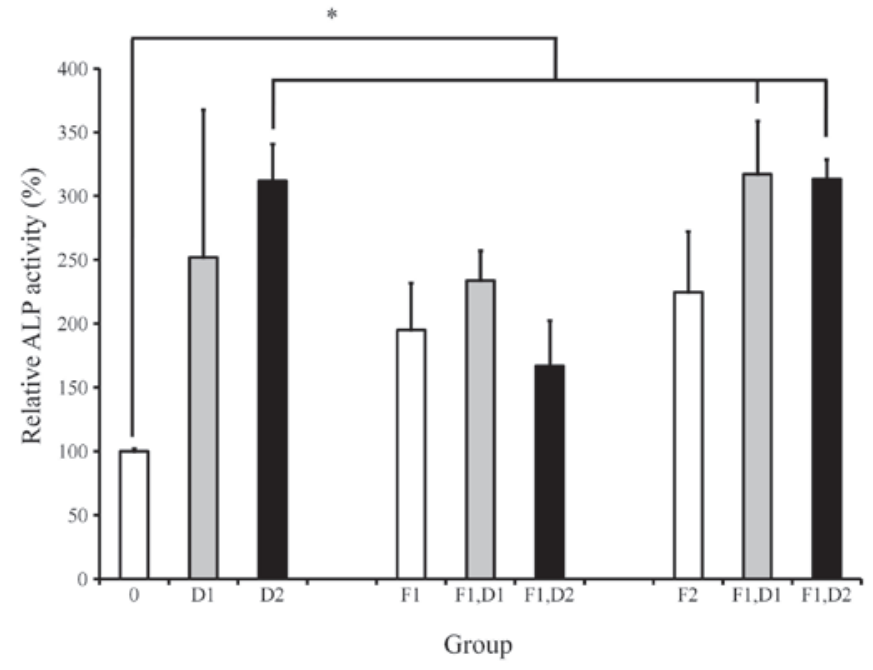

Figure 2. Relative value of ALP activity. "A statistically significant increase was observed when compared with the control (unloaded group) ( $\mathrm{P}<0.05$ vs. control).

$\mathrm{P}<0.05$ was considered to indicate a statistically significant difference.

\section{Results}

Protein measurement. The protein content in each culture plate was determined (Fig. 1). The results showed that the protein content of the cultures grown with the osteogenic differentiation media in the presence of FGF-2 at $2 \mathrm{ng} / \mathrm{ml}$ (F1) was increased compared with that of the control. However, the addition of dexamethasone to the cultures uniformly showed a decrease of protein content when compared with the dexamethasone-unloaded group.

ALP activity assay. ALP activity was increased when cells were treated with dexamethasone, with the highest value at $100 \mathrm{nM}$ (Fig. 2). Cultures grown in the presence of $20 \mathrm{ng} / \mathrm{ml}$ FGF-2 exhibited an increased value of ALP activity when compared with 10 and $100 \mathrm{nM}$ dexamethasone. Similarly, cultures grown in the presence of $20 \mathrm{ng} / \mathrm{ml} \mathrm{FGF}-2$ and $10 \mathrm{nM}$ 
A
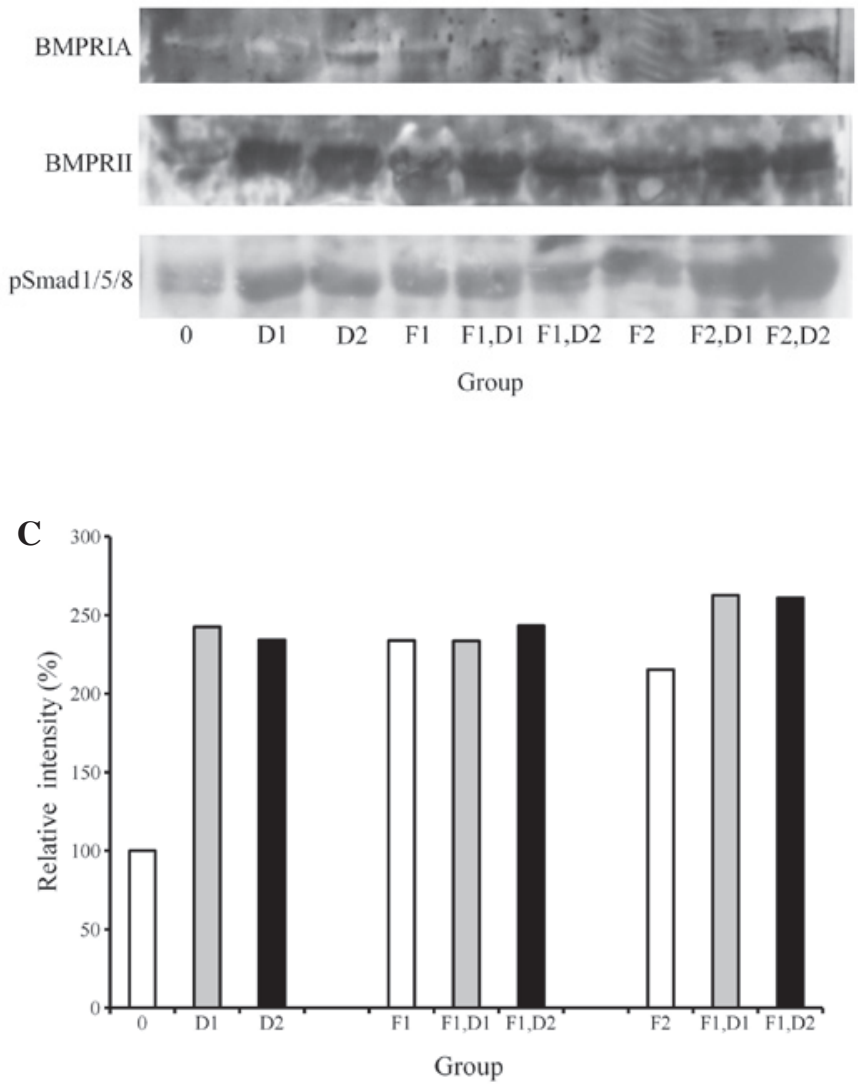
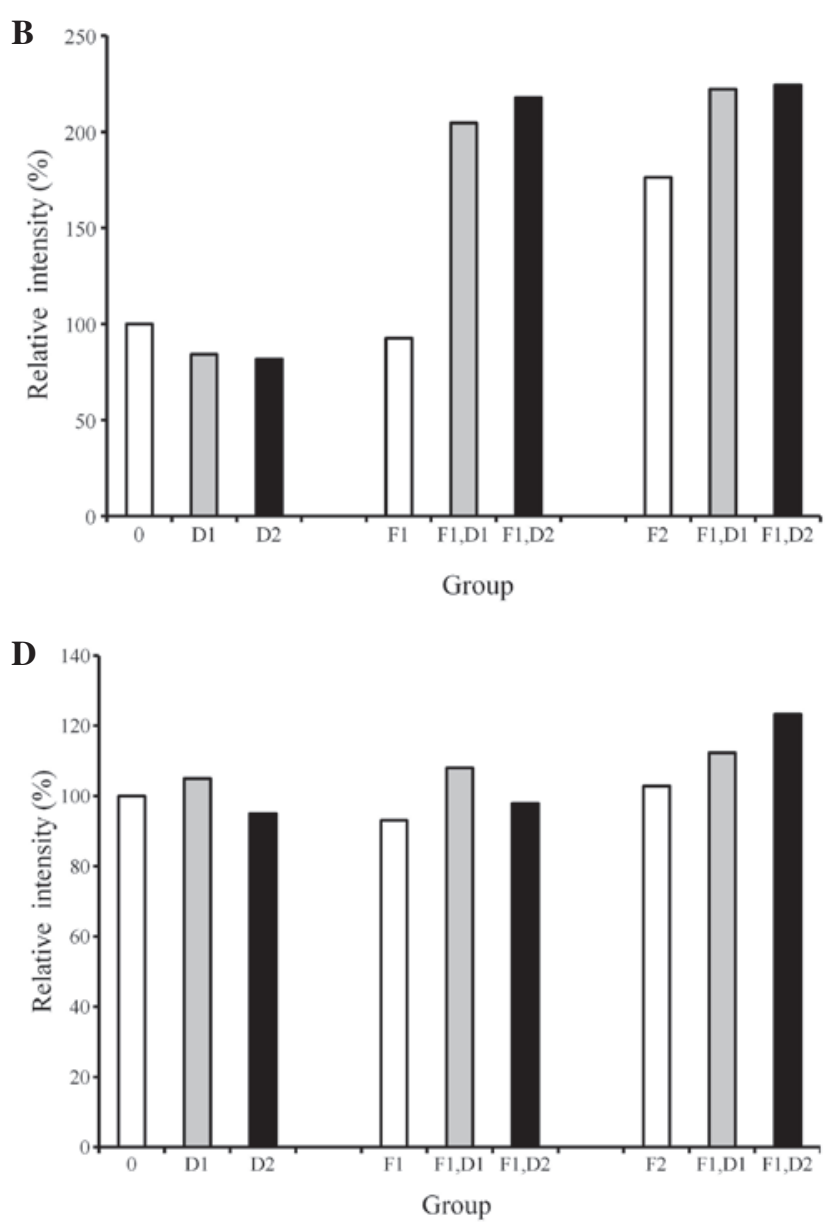

Figure 3. (A) Western blot analysis to detect the protein expression of bone morphogenetic protein receptor-IA, bone morphogenetic protein receptor-II and phosphor-Smad1/5/8. (B) Quantitative analysis of the protein expression of bone morphogenetic protein receptor-IA by densitometry. (C) The relative expression of bone morphogenetic protein receptor-II. (D) The relative value for the protein expression of phosphor-Smad1/5/8.

dexamethasone exhibited an increased value of ALP activity when compared with the $10 \mathrm{nM}$ dexamethasone-only group. The addition of $20 \mathrm{ng} / \mathrm{ml} \mathrm{FGF-2} \mathrm{to} 100 \mathrm{nM}$ dexamethasone resulted in an increase of ALP activity in comparison with that of the $100 \mathrm{nM}$ dexamethasone group. However, statistically significant differences were not observed $(\mathrm{P}>0.05)$.

Western blot analysis. A western blot analysis was performed to detect the protein expression following treatment with dexamethasone and FGF-2 (Fig. 3A). The results showed that the addition of $20 \mathrm{ng} / \mathrm{ml} \mathrm{FGF-2} \mathrm{and} 100 \mathrm{nM}$ dexamethasone appeared to increase the expression of BMPRIA and BMPRII (Fig. 3B and C). Similarly, the combination of $20 \mathrm{ng} / \mathrm{ml} \mathrm{FGF-2}$ and $100 \mathrm{nM}$ dexamethasone produced the highest $\mathrm{pSmad} 1 / 5 / 8$ expression, yielding $260 \%$, while the untreated control was considered to be $100 \%$ (Fig. 3D).

\section{Discussion}

In the current study, the combined effects of dexamethasone and FGF-2 on protein content, differentiation and protein expression of osteoblast progenitor cells under predetermined concentrations (10 and $100 \mathrm{nM}$ dexamethasone; 2 and $20 \mathrm{ng} / \mathrm{ml}$ FGF-2) were studied. The study examined the mechanisms of dexamethasone and FGF-2 on the regulation of the protein expression in mouse preosteoblastic cells. In addition, evaluations were conducted to identify whether combinations of dexamethasone and FGF-2 produced effects additively, synergistically or competitively.

An increase in protein content was achieved with the 2 ng/ml FGF-2 group under osteogenic differentiation media. This is in agreement with a previous report demonstrating that FGF-2 affected the proliferation and differentiation of the tested cells (14).

The treatment of dexamethasone on the preosteoblast clearly showed an increased level of ALP activity. This is similar to previous reports which showed that treatment with $10^{-8}$ to $10^{-7} \mathrm{M}$ dexamethasone presented a significant induction in the ALP activity of human bone marrow cells, leading to the osteoblast differentiation of bone marrow cells $(4,16)$. The current study showed that the addition of $20 \mathrm{ng} / \mathrm{ml} \mathrm{FGF-2} \mathrm{to}$ $100 \mathrm{nM}$ dexamethasone produced an increase in ALP activity in comparison with that of the $100 \mathrm{nM}$ dexamethasone group, however, this was not observed to be statistically significant.

Since BMP pathways are involved in osteoblast differentiation, factors associated with BMP signaling were evaluated (17). The present study clearly showed that the expression of BMPRIA and BMPRII was affected with the treatment of dexamethasone and FGF-2. Previous reports have shown that BMPRIA and BMPRII were induced by BMP-2 
and it was hypothesized that the induction of BMPRIA and BMPRII may be sufficient for the induction of bone formation $(14,18)$. The current study has demonstrated that the combination of $100 \mathrm{nM}$ dexamethasone and $20 \mathrm{ng} / \mathrm{ml} \mathrm{FGF-2}$ produced the highest expression of BMPRIA and BMPRII, leading to the highest value of $\mathrm{pSmad} 1 / 5 / 8$ expression.

The results, in terms of the effect of the combination of dexamethasone and FGF-2 on osteoblastic differentiation may be controversial, due to the different systems, maturation stages of the cells studied, heterogenicity of the osteoblast population, culture conditions and species differences $(2,19)$.

Within the limits of this study, dexamethasone significantly enhanced osteoblast differentiation, however, the combined delivery of dexamethasone and FGF-2 did not produce synergistic effects on osteoblast differentiation under the current experimental conditions. Additional studies are required to evaluate divergent conditions to select the optimal dosage and selective timing for the delivery of the agents.

\section{Acknowledgements}

This study was supported by Seoul St. Mary's Clinical Medicine Research Program 2013 through the Catholic University of Korea.

\section{References}

1. Naik PN, Chimatadar SA and Nandibewoor ST: Interaction between a potent corticosteroid drug - dexamethasone with bovine serum albumin and human serum albumin: a fluorescence quenching and fourier transformation infrared spectroscopy study. J Photochem Photobiol B 100: 147-159, 2010.

2. Ishida Y and Heersche JN: Glucocorticoid-induced osteoporosis: both in vivo and in vitro concentrations of glucocorticoids higher than physiological levels attenuate osteoblast differentiation. J Bone Miner Res 13: 1822-1826, 1998.

3. Atmani H, Chappard D and Basle MF: Proliferation and differentiation of osteoblasts and adipocytes in rat bone marrow stromal cell cultures: effects of dexamethasone and calcitriol. J Cell Biochem 89: 364-372, 2003.

4. Coelho MJ and Fernandes MH: Human bone cell cultures in biocompatibility testing. Part II: effect of ascorbic acid, beta-glycerophosphate and dexamethasone on osteoblastic differentiation. Biomaterials 21: 1095-1102, 2000.

5. Hakki SS, Nohutcu RM, Hakki EE, Berry JE, Akkaya MS and Somerman MJ: Dexamethasone and basic-fibroblast growth factor regulate markers of mineralization in cementoblasts in vitro. J Periodontol 76: 1550-1558, 2005.
6. Mansukhani A, Bellosta P, Sahni M and Basilico C: Signaling by fibroblast growth factors (FGF) and fibroblast growth factor receptor 2 (FGFR2)-activating mutations blocks mineralization and induces apoptosis in osteoblasts. J Cell Biol 149: 1297-1308, 2000.

7. Xiao G, Jiang D, Gopalakrishnan R and Franceschi RT: Fibroblast growth factor 2 induction of the osteocalcin gene requires MAPK activity and phosphorylation of the osteoblast transcription factor, Cbfa1/Runx2. J Biol Chem 277: 36181-36187, 2002.

8. Sobue T, Naganawa T, Xiao L, et al: Over-expression of fibroblast growth factor- 2 causes defective bone mineralization and osteopenia in transgenic mice. J Cell Biochem 95: 83-94, 2005.

9. Kotev-Emeth S, Pitaru S,Pri-Chen S and Savion N: Establishment of a rat long-term culture expressing the osteogenic phenotype: dependence on dexamethasone and FGF-2. Connect Tissue Res 43: 606-612, 2002.

10. Lee SY, Lim J, Khang G, et al: Enhanced ex vivo expansion of human adipose tissue-derived mesenchymal stromal cells by fibroblast growth factor-2 and dexamethasone. Tissue Eng Part A 15: 2491-2499, 2009.

11. Park JB: Low dose of doxycyline promotes early differentiation of preosteoblasts by partially regulating the expression of estrogen receptors. J Surg Res 178: 737-742, 2012.

12. Park JB: The effects of dexamethasone, ascorbic acid, and $\beta$-glycerophosphate on osteoblastic differentiation by regulating estrogen receptor and osteopontin expression. J Surg Res 173: 99-104, 2012.

13. Park JB: Combination of simvastatin and bone morphogenetic protein-2 enhances differentiation of osteoblastic cells by regulating the expressions of phospho-Smad1/5/8. Exp Ther Med 4: 303-306, 2012.

14. Park JB: Effects of fibroblast growth factor 2 on osteoblastic proliferation and differentiation by regulating bone morphogenetic protein receptor expression. J Craniofac Surg 22: 1880-1882, 2011.

15. Park JB: Effects of doxycycline, minocycline, and tetracycline on cell proliferation, differentiation, and protein expression in osteoprecursor cells. J Craniofac Surg 22: 1839-1842, 2011.

16. Beloti MM and Rosa AL: Osteoblast differentiation of human bone marrow cells under continuous and discontinuous treatment with dexamethasone. Braz Dent J 16: 156-161, 2005.

17. Fakhry A, Ratisoontorn C, Vedhachalam C, et al: Effects of FGF-2/-9 in calvarial bone cell cultures: differentiation stage-dependent mitogenic effect, inverse regulation of BMP-2 and noggin, and enhancement of osteogenic potential. Bone 36: 254-266, 2005.

18. Nakamura Y, Wakitani S, Nakayama J, Wakabayashi S, Horiuchi $\mathrm{H}$ and Takaoka K: Temporal and spatial expression profiles of BMP receptors and noggin during BMP-2-induced ectopic bone formation. J Bone Miner Res 18: 1854-1862, 2003.

19. Kim CH, Cheng SL and Kim GS: Effects of dexamethasone on proliferation, activity, and cytokine secretion of normal human bone marrow stromal cells: possible mechanisms of glucocorticoid-induced bone loss. J Endocrinol 162: 371-379, 1999. 